\title{
Developing Criteria for Complementary Health Insurance (CHI) Benefit Packages for a Medical Service Insurance Organization in Iran: A Qualitative Content Analysis
}

\author{
Nasser Saravi ${ }^{1}$, Rouhollah Zaboli ${ }^{1}$, Ali Hassanzadeh ${ }^{2}$, Farshad Najafipour ${ }^{3}$, Aziz Rezapour ${ }^{4}$, Majid Rezai-Rad ${ }^{5}$, Shahram \\ Tofighi $^{6, *}$ \\ ${ }^{l}$ Department of Health Services Management, School of Health, Baqiyatallah University of Medical Sciences (BUMS), Tehran, Iran \\ ${ }^{2}$ Ophthalmologist, Chairman of Iran Health Insurance Organization, Tehran, Iran \\ ${ }^{3}$ AJA University of Medical Sciences, Tehran, Iran \\ ${ }^{4}$ Department of Health Economics, Health Management and Economics Research Center, School of Health Management and Information \\ Sciences, Iran University of Medical Sciences (IUMS), Tehran, Iran \\ ${ }^{5}$ Department of Management, IRI Police University, Tehran, Iran \\ ${ }^{6}$ Health Management Research Center, School of Health, Baqiyatallah University of Medical Sciences (BUMS), Tehran, Iran
}

*Corresponding Author: Shahram Tofighi, Assistant Professor, Health Management Research Center, Baqiyatallah University of Medical Sciences (BUMS), Tehran, Iran. Email: shr_tofighi@yahoo.com

\begin{abstract}
Introduction: Development of Complementary Health Insurance (CHI) benefit packages has always been one of the main challenges of Health Insurance Organizations in Iran. Records related to developing a health insurance package in Iran show that there is no specific criterion for developing such packages. This study aimed at developing criteria for providing $\mathrm{CHI}$ benefit packages presented by the Medical Service Insurance Organization in Iran.

Methods: The current research is a qualitative and applied research which has been conducted in 2014. The sample size included 24 authorities in the domain of CHI, and a semi-structured interview was used for collecting data. Data analysis was based on framework method applying Atlas-Ti 5.2 software.

Results: Nineteen main themes and 53 sub-themes and finally 20 criteria were identified for four main dimensions of the benefit package including the insured, commitments of insurance services, financial resources and Medical Service Insurance Organization special priorities.

Conclusion: In this study, various criteria were identified for developing CHI. It seems that applying important criteria such as equity, clinical guidelines, effectiveness, and efficiency of CHI benefit package presented by Medical Service Insurance Organization can decrease the shortcomings of the current system and using standardization can lead to targeting the service benefit package, removing its defects and improving the health of insured people.
\end{abstract}

Keywords: Health Insurance, Health benefit Plans, Medical Service Insurance Organization, Iran

Article History: Received: 26 May. 2015; Accepted: 19 Sep. 2015; Online Published: 26 Nov. 2015

Cite this article as: Saravi N, Zaboli R, Hassanzadeh A, Najafipour F, Rezapour A, Rezai-Rad M, Tofighi S. Developing criteria for complementary health insurance (CHI) benefit packages for a medical service insurance organization in Iran: a qualitative content analysis. Int J Travel Med Glob Health. 2015;3(4):171-8.

\section{Introduction}

Today, all nations are faced with the fact that despite of unlimited human needs, resources are limited and all have a specific budget and they cannot spend beyond that $[1,2]$. Therefore, like other sectors, health sector is encountered with the limitation of resources [3]. The result of limitations of resources is encountering with the choices and selections. The need for choosing and allocating limited resources is the crucial duty of each government [4]. Considering these issues, it seems necessary to use the sources as efficiently as possible. For this purpose, determining the criteria and prioritizing them is necessary [5]. Due to budget constraints in developing countries such as Iran, this issue is more crucial [6] and determining the criteria and prioritizing them in health systems seems necessary.

Health insurance is usually offered in two forms- basic and complementary. The health insurance system is a part of each country's health system. Currently, the health insurance system in Iran consists of four types of organizations providing health insurance services such as Medical Service Insurance Organization (MSIO). These organizations are responsible for the basic health insurance service. The services of these organizations are often provided indirectly; these services are often bought from diagnostic and therapeutic centers under the contract with Medical Service
Insurance Organization [7]. Due to the increase in health care costs and inadequate coverage of basic health insurance obligations in Iran in recent years, the cost of payment by the insured has been dramatically increased. Therefore, some of these organizations use $\mathrm{CHI}$ besides basic insurance for increasing the financial protection of the insured.

While the overall cost index in Iran has been increased as much as 30 times during the last 20 years, the cost in the health sector has increased as much as 71 times. This has caused the health system to face many problems [8]. In the Iranian health care providing system, lack of health system in different levels and lack of universal health referral systems has led to the use of services more than what is needed, and incorrect use of financial and human resources has caused economic inefficiency. Lack of clinical guidelines, particularly with regards to the structure of the mentioned system has intensified this inefficiency [9].

Based on the study of Zare (2001), exceeding the slope of health care costs curve to Gross Domestic Product (GDP), lack of the possibility of using all medical facilities by the insured, and lack of coverage of some medical services by basic insurances indicates the necessity of a new approach towards $\mathrm{CHI}$ as one of the solutions for improving health insurance conditions [10]. Overall, it can be said that the purposes of the CHI are: filling the gap which exist in the 
services and liabilities of basic health insurance, providing conditions for innovation and variety and competition in the domain of health insurances emphasizing the cooperation of people in budgeting [11].

On the other hand, concerns regarding an increase in public expenditure on health care have gotten the attention of the policymakers around the world. Their attention towards establishing criteria and setting priorities in a way to develop the health insurance benefit package has always been one of the main challenges for insurance organizations. In other words, these organizations have always faced the question of what criteria should be concerned in developing services of this package considering the resources limitation. Without determining effective criteria and considering their role in developing health insurance benefit packages, these packages are politically unacceptable, financially impossible and technically inefficient. The package may also encounter with all the above problems simultaneously [1]. In this context, Oxman, Schünemann, \& Fretheim (2006) have recommended some criteria to be used by WHO for improving priority setting [12].

Many institutional methods have been developed to face the needs for adapting to the increasing demands coupled with inability to meet the demands of public financing [1315]. In practice, however, priority setting in health care and health insurance is subjective and occurs without any clear criteria, but evidences increasingly suggest that this approach is unacceptable [16]. Approaches for priority setting require clear and explicit discussion of the principles and criteria used for decision making in the field of health care and health insurance [17]. In this line, Asadi-Lari, Javadi, Naghavi, \& Gray (2004) emphasized on moving away from subjective instruments and criteria in priority settings towards using life quality as a criterion in determining the priorities [18]. The main question of this research was what criteria should be concerned for developing CHI presented by the Medical Service Insurance Organization.

Studies conducted for determining criteria and priority setting in developing countries indicates an imbalance between the criteria which are set based on priority setting and the criteria based on which the priority setting should be done $[19,20]$. Review of the literature indicates that lack of prediction of appropriate systems for developing an insurance benefit package is one of the most crucial problems in the Iranian insurance system [21]. Records related to developing Iran health insurance benefit packages indicates that there are no clear criteria for developing these packages (Sasannejhad, 1996). Preliminary studies on the current conditions of the insurance system in Iran shows that these conditions in the insurance system are encountered with many problems such as lack of clarity in the level of commitments in basic and complementary health insurance $[22,23]$. The decision regarding what should be added to the $\mathrm{CHI}$ benefit packages was based on specific criteria upon which agreement should be made. Generally, there is little agreement over what should be included in this package [24]. Considering what has been said so far, conducting research for determining the criteria for a $\mathrm{CHI}$ benefit package seems necessary and this study has been conducted in line with this approach.

\section{Methods}

The current study was an applied qualitative research conducted in 2014 using semi-structured interview. The focus of this study was mostly on how to determine the criteria for developing CHI presented by the Medical Service Insurance Organization in Iran. Accordingly, the population of this study consisted of 24 experts as key informants, which were chosen by a purposive sampling method [25] from some involved domains in $\mathrm{CHI}$ as following: 4 policy makers in CHI, 3 insured people, 5 people from medical diagnostic and therapeutic centers with contract with the Medical Service Insurance Organization, 2 directors of the Ministry of Health, 8 executive directors of $\mathrm{CHI}$, and 2 directors of other complementary health insurance in Iran. These people were chosen based on the following criteria: having at least five years of relevant managerial experience, having education in the field of medicine and paramedical and having related research trends, being a member of research committees or groups and having significant publications related to $\mathrm{CHI}$ fields.

A semi-structured interview was used for collecting the data. A total of 24 face to face interviews and five telephone interviews were conducted. Data collection was saturated by the 24th interview. For dependability and conformability of the text and the obtained criteria of interviews, transcriptions and tables of the classified themes and criteria were developed. Then content analysis of the documentations were presented to the university instructors who participated in the research and their views and suggestions were applied. The participated university instructors investigated the respondents' answers and unanimously came to some conclusions. Firstly, all CHI issues, which was to be mentioned scientifically and based on world experience, were responded. Secondly, during more than two hours of interview, the 23rd and 24th interviewees did not add more to what had been said by previous interviewees. Therefore, the instructors concluded that the obtained comments reached saturation and there was no need for further interview.

Generally, the health insurance benefit package can cover the dimensions of the overall population, the number and the characteristics of the service and the amount of coverage for medical expenses [26, 27]. Accordingly, the main concern of this research was to determine the criteria for the three dimensions of $\mathrm{CHI}$ including the insured (demographic characteristics such as age, type), the liability insurance services (including the type and quality of service) and financial resources (such as costs and premium). On the other hand, considering the specific priorities of the Medical Service Insurance Organization based on the opinions and assertions of the research experts and after consulting with instructors, it was decided to add this issue as the fourth dimension entitled as characteristics and special priorities of the Medical Service Insurance Organization (such as policymaking and planning).

For analyzing data, framework analysis was used. Framework analysis consists of five steps (familiarization, identifying a thematic framework, indexing, charting, and mapping and interpretation). This type of analysis is mostly used for analyzing qualitative data for policy-making studies. During the familiarization phase, the initial thematic framework was designed based on literature study, guide questions in interviews, thematic guidelines and after holding frequent meetings among the researchers. Each of the interviews were coded (indexed) separately and a list of these codes (indexes) with their relationship with the 
thematic framework of the interviews was extracted [28]. At this stage, one or two codes (indexes) were assigned for each which contained related information in the interviews [29]. After this stage, the relationship between main and subthemes were also identified and analyzed. Then, the stage of charting was conducted. The interpretation of each part of the thematic model was done in a process similar to the indexing stage.

In all the above steps, the Atlas-Ti 5.2 software was used. The thematic framework in the process of analysis was revised several times [30]. The primary framework which included four themes remained unchanged, but the subgroups of each theme were changed repeatedly during this process. In the final extraction and design of the qualitative structure model i.e. determining the criteria, the method of confirmation by experts was used- an effective and recognized method by experts in important qualitative studies. The ethical consideration in this study included resection, observation rights and trust of each participant, explanation of the purpose and nature of the research to the participants, ensuring confidentiality of participants' name and classified data. In the findings section the letter (R) with number means the respondent who has been quoted.

\section{Results}

Section 1. Themes: Based on conducted framework analysis, 19 main themes and 53 sub-themes were identified. In Table 1, each of these themes and sub-themes have been presented. In some of the sub-themes, direct quotation of some of the respondents has been added.

\subsection{The Insured}

3.1.1. Theme 1 (Types of the insured): Based on the expert's opinions, the insured were categorized in this section. They were categorized based on the types of organizational commitment, the level of health and type of service benefit package. "The insured can be divided into different categories: the employees, the retired people, the immediate family of employees and the retired people. Then, there is the category of the indecisive insured or more distant family, such as daughter-in-law, sister-in-law and grandchildren. It should be noted that the fathers and mothers of the employees and retired are also located on this continuum." (R20). With respect to the age of the insured people, one of respondents believed that: "In the domain of family, the needs for preventive dentistry for children, the needs of women with their specific conditions and the public health issues are the main concerns. In the domain of the retired people, issues such as geriatrics and rehabilitation as well as more advanced diseases such as cancer and cardiovascular are more crucial" (R4).

3.1.2. Theme 2 (Needs and preferences of the insured): By considering the specific occupational conditions that the insured are faced during their employment period, as well as their retirement, it can be said that the insured have different medical needs and preferences compared to the others in the society. Regarding empowering the insured, one of the respondents believed that: "It is very important for us to direct each targeted community purposefully towards our organization and cover the requirements of that community in the way that the satisfaction of the whole collection be fulfilled" (R1).

With respect to the increase of access to services, one of the experts stated that: "One issue that is very important to discuss is the purposeful access of all the insured to all kinds of services that the comprehensiveness of quality and simultaneous learning must be observed" (R2). In line with reducing huge costs, respondents have had different opinions: "There has been some attention to some types of the insured, such as veterans and patients with refractory diseases, etc., but it has not yet been enough" (R11).

3.1.3. Theme 3 (Informing the insured): In this regard, most respondents believed that the Medical Service Insurance Organization has not worked very well in this domain. Regarding the importance of time of access to information, respondents had different opinions: "Whenever the insured requires obtaining information about a specific issue, he/she should have access to required information" (R7).

With respect to the domain of purposeful informing, respondents believed that "Informing must be purposeful, i.e. each of the insured should be informed based on his/her needs" (R18).

\subsection{Insurance Services}

3-2-1. Theme 4 (Types of commitments): Regarding the variety of diagnostic and therapeutic service packages which are the liability of $\mathrm{CHI}$, the respondents stated that " $\mathrm{CHI}$ should cover all the service packages that are subject to basic and other insurances" (R13). "I think CHI should almost cover everything" (R23).

3.2.2. Theme 5 (Quality of insurance services): With respect to facilitating the services, respondents believed that "We must offer services that are actually required by the insured that is required for the insurance of their diseases. In fact, we would say that these services are fully compatible with the needs of the insured." (R3). To increase the quality of services, the participants believed that: "with respect to the adequacy, I think, still, there is more room for this package to be extended and it should cover all types of diseases" (R8).

3-2-3. Theme 6 (Medical centers under contract with insurance): The findings of the next section show that the respondents in the interview have focused on the positive interaction of the organization with the centers under the contract. "Providing and receiving services should be appropriate. For this purpose there should be appropriate interaction with the insured and the service providers". (R12). To define indexes for the centers under the contract, the respondents believed that "for efficiency, the role of the service providers becomes more significant; by defining some indexes, the mentioned centers, should try to provide the best quality and comprehensiveness of care. This is done to practically prove to the insured that they are entitled to receive the same services by the same premium" (R2).

3.2.4. Theme 7 (Supervising the insurance services): One of the important issues mentioned by some experts was lack of enough supervision on the performance of the stakeholders of the organization including the centers under contract and the insured. In this regard, one of the respondents believed that: "in many cases, there should be more supervision, i.e. for those who provide this service as well as those who receive the service" (R12). One of the participants, recognizing the need for continuous supervision of services, believed that: "Occasionally we should supervise these services.

It is not enough to just make a commitment, but what is necessary is that after some time we should supervise the services in order to find and fix the present defects." (R20). 
Table 1. Effective main themes and sub-themes in developing CHI benefit packages

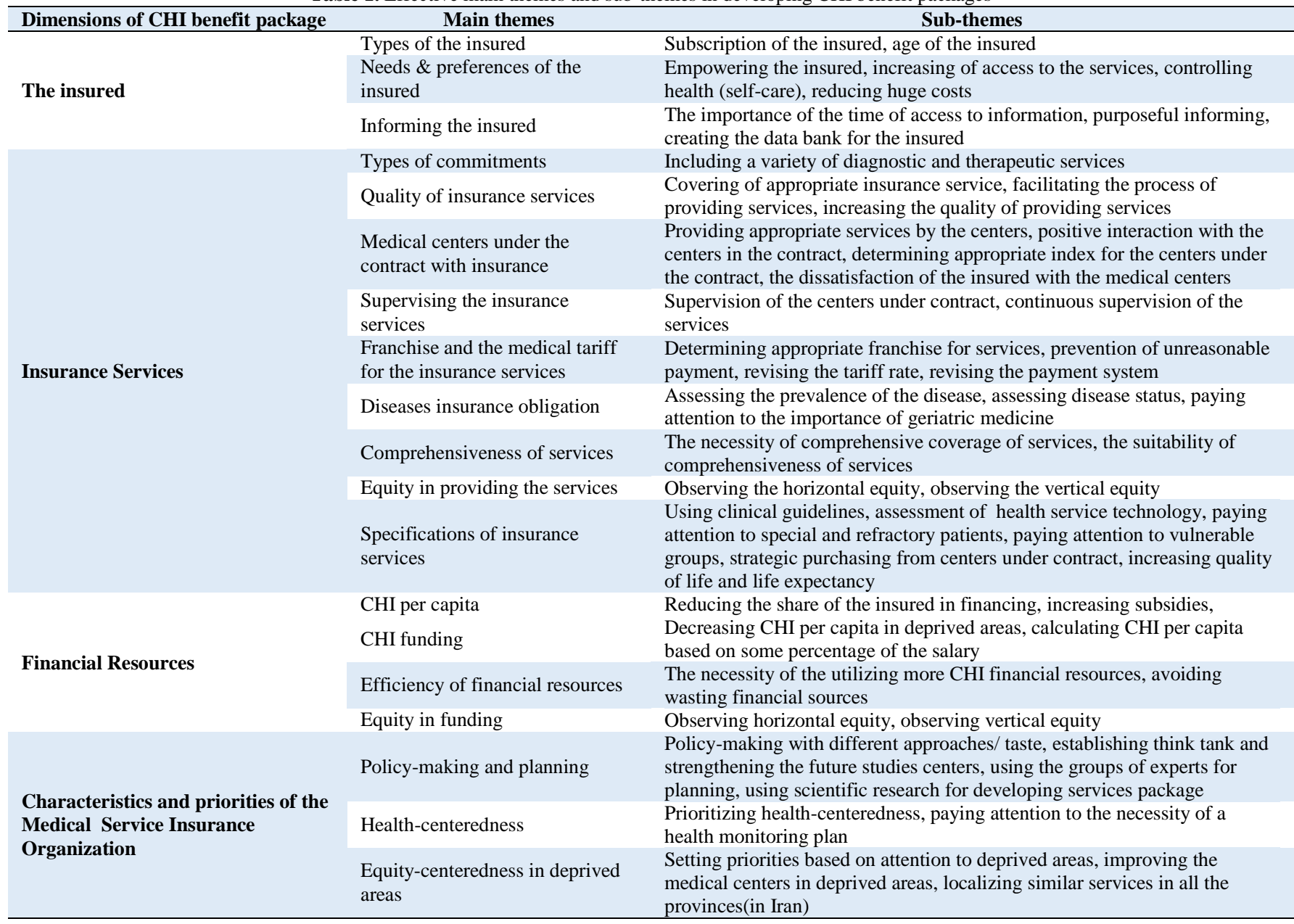

3.2.5. Theme 8 (Franchise and the medical tariff for the insurance services): In order to determine appropriate services franchise, one of the respondents believes that: "Everything should be free for the insured from outpatient to inpatients and dental problems which are fundamental problems" (R70). To prevent unreasonable payment, the participants believed that: "The more medical service tariffs are realistic, the more profit the insured achieve whether in health centers related to the organization or the centers not related to the organization" (R10). Regarding the review in the payment system, the belief was that "The ideal payment system is the one in which there is no financial relationship between the patient, doctor and the center" (M16).

3.2.6. Theme 9 (Diseases insurance obligation): In relation to services related to prevention, treatment and rehabilitation of patients, the participants believed: "In the field of health care and prevention, the insured require some preventing issues including screening test, the clinical examination, issues of dentistry, and sanitary issues which can prevent the diseases and leads to early detection of the diseases as well" (R5). For the assessment of disease types (infectious, communicable and newly emerged ones), participants also believed that "CHI should localize the services in accordance with the targeted population and the types of diseases in different geographies" (R1).

3.2.7. Theme 10 (Comprehensiveness of services): Regarding the requirement for comprehensiveness of services, the participants had different opinions: "The comprehensiveness of our services is totally different from the services of others and each of the services included in the basic as well as complimentary insurances are covered." (R3). Regarding the appropriateness comprehensive service coverage, the experts believed that "What the insured expect from the $\mathrm{CHI}$ is that all his/her medical expenses be paid. Therefore, the comprehensiveness of this insurance still does not existed" (R14).

3.2.8. Theme 11 (Equity in providing the services): In the area of health, observing equity is a special dimension. Talking about the horizontal equity, respondents stated that" population in remote areas uses fewer facilities while they give approximately equal per capita." (R6). Also, about the vertical equity, one of the participants stated that: "Vertical equity has been observed to some extent for people who are special due to their conditions and diseases." (M12).

3.2.9. Theme 12 (Specifications of insurance services): Participants in the interview referred to different positive and negative characteristics of CHI services. Regarding the use of clinical guidelines, the participants believed that: "One of the weaknesses of the insurance to prevent the violations is that it has not operated based on the guidelines" (R3). One of the issues mentioned in the statements of many interviewees was their emphasis on medical and financial support of special patients and refractory diseases: "The use of $\mathrm{CHI}$ for expensive treatments such as refractory, trauma, etc. is more important" (R13). Regarding the efficiency of the content of the CHI benefit packages, the respondents stated that:" We have tried to have the best quality and the maximum coverage with this per capita that can lead to the increase of 
life quality and expectancy among the insured." (R24).

\section{3-3. Financial Resources}

3.3.1. Theme 13 (CHI per capita): One of the participants stated that: "At the present, roughly more than $90 \%$ of per capita for CHI is paid by the insured" (R18). In order to reduce the per capita in deprived areas, the participants believed that "if someone works in deprived areas, his/her per capita should be lower and they should be provided with more services" (R14).

3-3.2. Theme 14 (CHI funding): In order to calculate the CHI per capita based on some percentage of salary, one of the participants stated that: "per capita should not be based on fixed premium. Like the basic insurance, it should be based on some percentage of salary, and this is somewhat closer to equity" (24R).

3-3-3. Theme 15 (Efficiency of financial resources): To meet all the requirements of utilizing more of $\mathrm{CHI}$ financial resources for the service benefit packages, the participants had different opinions: "We have tried to have the highest quality and coverage with this lower per capita (24R). Related to the sub-theme of prevention of wasting financial resources, participants believed that "Despite using a lot of financial sources in $\mathrm{CHI}$, the problems have not only decreased, but they are also increasing" (R2).

3-3-4. Theme 16 (Equity in funding): To observe equity in financing resources and the balance of premium paid by the insured, the participants stated that: "Regarding CHI per capita, we have administered the horizontal equity which is not an appropriate method" (R17). "Even if we don't want to seek to add something for receivers of insurance services who exceed in using the insurance services, we should decrease per capita for those who use fewer or less services" (R12).

\subsection{Characteristics and priorities of Medical Service Insurance Organization}

3-4-1. Theme 17 (Policy-making and planning for $\mathrm{CHI}$ ): According to the respondents, one of the main drawbacks has been the different approach/taste in dealing with policy making in the domain of CHI. "I think no specific criteria exists in this case. This means that $\mathrm{CHI}$ benefit packages are mostly determined based on the existed demands" (R20). Regarding the sub-theme of using experts for planning $\mathrm{CHI}$ benefit packages, the participants believed that: "In my opinion, all the people that I mention should be gathered in a work group, i.e. a team of experts from different sections of the health organization, and should have cooperation in policy-making and planning" (R3).

3-4-2. Theme 18 (Health-centeredness): For specific conditions of the insured and the continuous emphasis on maintaining their health, one of the experts believed that:" In my opinion, health-centeredness should be a rule in the organization." (R15).

3-4-3. Theme 19 (Equity-centeredness): In regards to the priority given to the deprived areas, some of the participants believed that: "Deprived areas should also be considered. Personnel who work in deprived areas should get more and better services; so that they will be willing to stay there and serve the people there." (R16). For the localization of the same services in all provinces (providing local services), participants believed that "The CHI should avoid a uniform and comprehensive program for all the population and move towards localizing the services in according with the covered population in various geographies" (R2).

Section 2. Criteria: The relationship between the main and sub-themes, based on conducting framework analysis, was identified and Table 2 was completed. Then, for extraction and final designing of qualitative model or determining the criteria, the method of approval by experts was used in the way that, at first, the related content criteria were approved by the instructors and experts. Then, by convening an expert panel, discussions were done again by some experienced instructors and exports for each of the criteria and their proportion for determining the validity of criteria. Using the recommendations and their final approval, the scientific validity was confirmed and finally the localized criteria of the CHI benefit packages were determined. Therefore, the main finding of this research is shown in Table 2.

\section{Discussion}

Determination of the health insurance benefit packages has been one of the main challenges of insurance organizations. In other words, these organizations have always been faced with the question that what criteria should be considered for such benefit packages considering the limitation of resources [1]. There is no single method for priority setting which is ideal for all countries [31]. Despite different economic, ethical and procedural approaches in the domain of priority setting, there is no golden rule or standard for this work [32]. Therefore, we should pay attention to two important points. Firstly, based on what criteria the decisions are made and secondly, how much these criteria are effective in decision making.

According to the results of table 2, twenty criteria were identified and extracted. According to other researches, many of these criteria in establishing CHI benefit packages were emphasized by many experts. In this regard, a comparative study was done in 2005 on three countries which were Germany, England and Switzerland.

Table 2. Criteria for developing CHI benefit packages

\begin{tabular}{|c|c|}
\hline $\begin{array}{l}\text { Dimensions of CHI } \\
\text { benefit package }\end{array}$ & $\begin{array}{c}\text { Criteria for developing CHI benefit } \\
\text { packages }\end{array}$ \\
\hline \multirow{3}{*}{ The insured } & 1. The subscription of the insured \\
\hline & 2. The age of the insured \\
\hline & 3. Empowering the insured \\
\hline \multirow{11}{*}{ Insurance Commitments } & $\begin{array}{l}\text { 4. Variety in the content of CHI benefit } \\
\text { packages }\end{array}$ \\
\hline & 5. Level of service quality \\
\hline & 6. Induced demand management \\
\hline & 7. Management of costs \\
\hline & 8. Portion of payment by the insured \\
\hline & 9. The most costly prevalent diseases \\
\hline & 10. Comprehensiveness of service packages \\
\hline & 11. Equity in providing services \\
\hline & 12. The use of clinical guidelines \\
\hline & 13. Refractory patients \\
\hline & 14. Effectiveness of service package \\
\hline \multirow{3}{*}{ Financial Resources } & $\begin{array}{l}\text { 15. The rate of participation of the insured in } \\
\text { providing per capita }\end{array}$ \\
\hline & 16. The efficiency of service packages \\
\hline & 17. Equity in financing resources \\
\hline \multirow{3}{*}{$\begin{array}{l}\text { Specifications and } \\
\text { priorities of the medical } \\
\text { service insurance } \\
\text { organization }\end{array}$} & 18. Evidence-based policy-making \\
\hline & 19. Health-centeredness \\
\hline & 20. Equity-centeredness in deprived areas \\
\hline
\end{tabular}


The procedures and criteria for developing benefit packages were identified and evaluated. Among the criteria for developing benefit packages in these countries, issues such as medical necessity, effectiveness, efficiency, cost of services, the effectiveness of new services, the clearness, and group participation can be mentioned [33]. Kapiriri \& Norheim (2004) in their study entitled "Criteria for Prioritysetting in Health Care in Uganda: Exploration of Stakeholders' values " which was done for the purpose of determining criteria for priority setting in health care, categorized the criteria into patient-related, disease-related and society-related criteria [17]. Council on Ethical and Judicial Affairs (CEJA) of American Medical Association in 1995, after investigation, recommended these criteria: "likelihood of benefit to the patient, impact of treatment on the patient's quality of life, duration of the benefit, urgency of the patient's need, $\&$ all else being equal: the amount of resources required for successful treatment"[34]. Makundi, Kapiriri, \& Norheim (2007) used the criteria of equity, severity of disease, age, patient groups and the capacity of benefits for determining health service packages and priority settings [35].

In the recent decades, investigation and evaluation of the process of determining criteria and priority setting in health systems have always been of interest for researchers, but this subject has been less studied in Iran. For instance Tourani, Amiresmaili, Maleki, \& Hadian (2009) investigated the current situation of priority setting in providing health services in Iran [36] . Kabir et al. (2013) in their research entitled "Determining Criteria for Designing Health Benefit Packages in Selected Countries" emphasized the criteria of availability, cost-effectiveness, cost and quality of services for developing health service benefit packages in Iran [37].

In general, the effective criteria for developing $\mathrm{CHI}$ benefit packages in this study such as quality of services, effectiveness, cost of services, service effectiveness, equity, type of diseases, and the age of the insured have been in accordance with the findings of other studies. However, considering the special conditions of the insured by the Medical Service Insurance Organization and looking at the special priorities, some of these criteria such as empowering the insured, health-centeredness, equity-centeredness in the deprived areas, induced demand management, comprehensiveness of service benefit package, and evidence-based policy with a more professional look were more emphasized by interviewees.

According to the findings of this study, paying attention to some issues seems necessary. Firstly, lack of cooperation of different groups in developing the benefit packages (themes 1,2 and 17), was one of the criticism of the current package. The legitimacy of the procedures and criteria in developing CHI benefit packages depends on the presence of the representatives of all stakeholders [33]. This is while, the involvement of the public, increases the accountability and causes the authorities to act more clearly on developing $\mathrm{CHI}$ benefit packages and its priority setting [38]. The second point is the weakness in informing the insured about the content of the $\mathrm{CHI}$ benefit packages and other dimensions related to it (theme 3); this is an important defect that should be remedied as soon as possible. Another point is that applying the methods of providing health services and the method of funding to establish the criteria of equity in utilizing them (themes 11 and 16), were the most important issues for experts. The next point is that supporting insured individuals with refractory diseases and vulnerable people (theme 2) in organizations should be regarded as a permanent need.

There are other points which must also be considered. An appropriate combination of methods of payment should be used (Theme 8). The method of payment should be in such a way that the insured pay more for more health maintenance (not for more service provided). One of the obstacles for developing an appropriate benefit package is the lack of adequate information regarding related scientific methods (themes 12 and 17). To resolve this problem, recommendations such as education policy making, establishing think tanks and future studies centers, and using scientific methodology were presented in developing benefit packages. An advisory committee at the beginning of developing benefit packages and priority setting (themes, 1, 6 and 17) should be established. This committee should apply the view of stakeholders and experts in determining priorities which can lead to realistic priority setting, facilitation in implementing suggested priorities and the decrease of resistance to implementing suggestions for improvement. Finally, based on the findings, it seems that developing appropriate $\mathrm{CHI}$ benefit packages by the Medical Service Insurance Organization requires a systematic view to this issue as well as designing a long-term program (themes 2, 5, 10, 14 and 17). This program should systematically involve the criteria for benefit package which were determined through this study.

\section{Conclusion}

The focus of this study was to identify and determine different criteria for developing a CHI benefit package. Therefore, the study tried to localize its results with the opinions of specialists and experts in the study. With proper implementation, these criteria can be identified and exploited. It seems that lack of attention to appropriate criteria and not considering the importance and interaction of these criteria with each other are the most important factors that can lead to failure of the activities for developing $\mathrm{CHI}$ benefit packages.

In summary, it can be concluded that, adoption of important criteria such as equity, clinical guidelines, effectiveness, efficiency, reliability of documents and evidences, management of costs in addition to other criteria relevant to the intervention, the disease, the insured and the providers of $\mathrm{CHI}$ benefit packages decreases the shortcomings of the current system. Standardization can also lead to content targeting of the benefit package and removing its current deficiencies and, in all, could result in increasing the health level of the insured.

The need for determining the criteria and priority setting are inevitable. This is because no amount of resources would ever be able to meet all the needs and demands of the insured. Therefore, the researchers believe that appropriate development of the $\mathrm{CHI}$ benefit package requires a systematic and coherent view. This approach should be in accordance with statutory criteria and the updated knowledge and systematically monitor the changes in each element of a country's health system as well as considering these changes on the other elements.

It should be noticed that due to regular development of science and technology, and the provision of new methods of diagnosis and treatment, authorities should consider the introduction, establishment and the provision of diagnostic 
and treatment services. They should also consider the level of the modern medical services in accordance with the abilities of the organization and the insured in funding the cost of health considering the criteria extracted from scientific evaluation of health care. Comprehensive and purposive policies should also be adopted for providing the insured with health and avoiding burden on them due to the huge cost of the diseases. In this line, it is suggested that the determined criteria in the research be announced to the executives by the main policy-makers so that they can consider these criteria in developing $\mathrm{CHI}$ benefit package.

\section{Limitations}

Limited research done in the field of criteria for developing $\mathrm{CHI}$ benefit packages and its effects as well as the difficult accessibility to some documents were the limitations of this research. However, all attempts were done to resolve these limitations as much as possible.

\section{Acknowledgements}

The authors of this article appreciate those who spent their valuable time for getting interviewed and those who helped us in preparing this paper, especially Dr. Mehdi Ebrahimnia.

\section{Authors' Contributions}

All the authors were involved in the study design and result interpretation. Also, all the authors confirmed the final draft before submission.

\section{Financial Disclosure}

The authors declared no financial disclosure.

\section{Funding/Support \\ Not declared}

\section{References}

1. Dehnavieh R, Tabibi SJ, Maleki M, Rashidian A, Noorihekmat S. Information Criteria for Basic Health Insurance Package in Iran from Health Insurance Organizations View. Health Info Manag. 2010;7(2):109-18. Persian

2. Williams A. Priority setting in public and private health care: a guide through the ideological jungle. J Health Econ. 1988;7(2):173-83.

3. Bobadilla JL. Searching for essential health services in low-and middle-income countries: a review of recent studies on health priorities Washington DC: Inter-American Development Bank; 1998. Available from: http://publications.iadb.org/bitstream/handle/11319/5310/Searching $\% 20$ for $\% 20$ Essential $\% 20$ Health\%20Services\%20in\%20Low\%20an d\%20Middle $\% 20$ Income $\% 20$ Countries.pdf?sequence $=1$

4. Ham C, Coulter A. The Global Challenge of Health Care Rationing International Experience of Rationing (or priority setting). Philadelphia: Open University Press. 2000: 1-12. Buckingham.

5. Segal L, Chen Y. Priority Setting Models for Health: The Role for Priority Setting and A critique of alternative models A Summary. Report to the Population Health Division (Working Paper 119). Centre for Health Program Evaluation (CHPE). 2001. English. Retrieved

http://www.buseco.monash.edu.au/centres/che/pubs/wp119.pdf

6. Tourani S, Maleki MR., Hadian M, Amiresmaili MR. Survey on present status of health services priority setting in Iran. Payesh. 2011;10(2):217-30. Persian

7. Ministry of Labour and Social Affair IRoI. Health care system 2014 Persian. Available from: http://www.mcls.gov.ir/fa/news/43824

8. Central Bank of Islamic Republic of Iran. Selected Economic Indicators 2015. Persian. Retrieved from http://www.cbi.ir/simplelist/SelectedEconomicIndicators_en.aspx

9. Davari M, Haycox A, Walley T. The Iranian health insurance system; past experiences, present challenges and future strategies. Iran $\mathbf{J}$ Public Health. 2012;41(9):1-9.
10. Zare H. A brief introduction to complementary health insurance. Public Health Insurance Journal. 2001;19(5):20-33. Persian

11. Hassanzadeh A. Proceeding of 27th International Social Security Association General Assembly (ISSA). Tehran: Scientific and Cultural publisher. 2002:144-3. Persian

12. Oxman AD, Schünemann HJ, Fretheim A. Improving the use of research evidence in guideline development: 2. Priority setting. Health Res Policy Syst. 2006;4(14).

13. Saltman RB, Figueras J. European healthcare reforms; Analysis of current strategies WHO Regional Publications,European Series. 1997;72. Summary Retrieved from http://www.euro.who.int/_data/assets/pdf_file/0005/111011/sumhe careform.pdf?ua $=1$

14. Abel-Smith BFJ, Holland W, Mckee M, Mossialos E. Choices in health policy; an agenda for European union. 1st Edition. Dartmouth Publisher Company: Aldershot, 1997.

15. New B, King Edward's Hospital Fund for London. Rationing talk and action in health care. 1s t Edition .King's Fund and BMJ Publishing: London, 1997.

16. Hauck KSP, Goddard M. The Economics of Priority Setting for Health Care: A Literature Review (Health, Nutrition and Population (HNP) Discussion Paper). Washington, DC: World Bank. 2004. Retrieved from http://hdl.handle.net/10986/13700

17. Kapiriri L, Norheim OF. Criteria for priority-setting in health care in Uganda: exploration of stakeholders' values. Bull World Health Organ. 2004;82(3):172-9

18.Wellington, New Zealand: 5th International Conference on Priorities in Health Care; 2004. The role of Health Related Quality Of Life (HRQL) measurement in setting priorities in the Iranian health care system; p. 1-142.

19. Kapiriri L, Norheim OF, Heggenhougen K. Using the burden of disease information for health planning in developing countries: the experience from Uganda. Social Sci Medi. 2003;56(12):2433-41.

20. Kapiriri L, Martin DK. A strategy to improve priority setting in developing countries. Health Care Analysis. 2008;15(3):159-67.

21. Danesh-Dehkordi N. Health universal coverage from law perspective. Health Insurance Organization(Scientific and Cultural Publication). 2004, Tehran: Medical Service Insurance Organization. Persian

22. Sasannejhad AH. Complete set of rules and regulations of the NHS. Tehran: Medical Service Insurance Organization. 1996. Persian

23. Hossein Z. Health systems in the world. 1st Edition. Health insurance organization: Tehran, 2004. Persian

24. Wong H, Bitran R, Shepard D, Thompson M. Designing a benefits package: cost- effectiveness analysis in health(Prepared for the Flagship Course on Health Sector Reform and Sustainable Financing World Bank Institute). World Bank Institute (WBI). 1999; First principles. English. $\quad$ Retrieved from http://info.worldbank.org/etools/docs/library/122031/bangkoked/ba ngkokmarch05/week1/4thursday/s2servicedelivery/designingabenef itpackage.pdf

25. Lai-Kow Chan, Wu ML. Quality Function Deployment in Services: A literature review. Eur J Oper Res. 2002;143(3):463-97.

26. Mohebifar R, Tabibi S, Asefzadeh S. Design of Disaster Management Structure Pattern for Iran. Health Manag J. 2008;11(33):47-56. Persian

27. Schreyögg J, Stargardt T, Velasco-Garrido M, Busse R. Defining the "Health Benefit Basket" in nine European countries. Eur J Health Econ. 2005;6(1):2-10.

28. Lacey A LD. Trent focus for research and development in primary health care: to qualitative analysis. Unpublished manuscript: Trent Focus, Nottingham. 2001

29. Pope C ZS, Mays N. Qualitative research in health care: analysing qualitative data. British Medical Journal (BMJ) 2000;320(7227):114-6. Retrieved from http://www.ncbi.nlm.nih.gov/pmc/articles/PMC1117368/pdf/114.pdf

30. Bryman A, \& Burgess, R. G. Burgess RG. Analyzing Qualitative Data. Routledge, 1994.

31. Rosen S, Sanne I. Rationing Antiretroviral Therapy for HIV/AIDS in Africa: Choices and consequences. PLoS Med. 2005;2(11):303.

32. Lammintakanen J. Health care prioritization, Evolution of the Concept, Research and policy process faculty of social sciences of the university of Kuopio. Department of health policy and management. 2005. University of Kuopio, Faculty of Social Sciences, Finland, 2005.

33. Greß S, Niebuhr D, Rothgang H, Wasem J. Criteria and procedures for determining benefit packages in health care: A comparative perspective. Health Policy. 2005;73(1):78-91. 
34. Leggat $\mathrm{S}$. Developing a clinical priority setting framework, 1st ed Melbourne : South Australian Department of Health. Adelaide and La Trobe University, school of public health. 2004. English. Retrieved from https://www.researchgate.net/profile/Sandra Leggat/publication/367 23083_Developing_a_clinical_priority_setting_framework/links/02 bfe510ee85ac6d95000000.pdf

35. Makundi E, Kapiriri L, Norheim OF. Combination evidence and values in priority setting: testing the balance sheet method in a lowincome country. BMC Health Serv Res. 2007;7(1):152.

36. Tourani S, Maleki MR, Hadian M, Amiresmaili MR. An interview survey on health priority setting practice in Iran. Res J Biol Sci. 2009;4(11):1193-201. Persian

37. Kabir MJ, SoudabehVatankhah BD, Ravaghei H, Jafari N, Heidari A Behnampour N, et al. Determinant Criteria for Designing Health Benefit Package in Selected Countries. Life Sci J. 2013;10(3):1392403.

38. Wiseman V MG, Berry G, Tang K. Involving the general public in priority setting: Experiences from Australia. Social Sci Med. 2003;56(5):1001-12. 